\title{
LA LEXICOGRAFÍA ENTRE EL CATALÁN Y EL CASTELLANO (XVI-XIX) Y SU PROYECCIÓN EN EL Diccionari de Pere LAbernia
}

\author{
Cristina Gelpi \\ Universitat Pompeu Fabra
}

RESUMEN

La lexicografia bilingüe entre el catalán y el castellano se inicia durante el siglo XVI y progresa de forma constante hasta nuestros días. Su evolución refleja la situación sociolingüistica del catalán. El Diccionari de la llengua catalana ab la correspondencia castellana y llatina, de Pere Labernia, puede ser considerado un precursor de la lexicografia bilingüe actual. El artículo describe las generalidades de la lexicografia bilingüe catalán-castellano entre los siglos XVI y XIX y se centra en las características principales de la obra de Labernia.

Palabras clave: diccionario bilingüe; lexicografia bilingüe; catalán-castellano; Diccionari Labernia.

ABSTRACT

The bilingual lexicography between Catalan and Spanish starts during the $16^{\text {th }}$ century and it develops in a constant progression until the present. It reflects the sociolinguistic situation of the Catalan language. The bridge between the ancient bilingual lexicography and the modern one can be represented by the Labernia's Diccionari de la llengua catalana ab la correspondencia castellana y llatina. The article describes the generalities of the evolution of the bilingual Catalan-Spanish dictionaries (XVI-XIX) and focuses on the main features of the Labernia Dictionary.

Keywords: bilingual dictionary; bilingual lexicography; Catalan-Spanish lexicography; Labernia Dictionary.

\section{Presentación}

La relación lexicográfica bilingüe y plurilingüe entre el castellano y el catalán es antigua; se inicia a lo largo del siglo XV y se desarrolla de forma constante hasta el día de hoy. En sus orígenes se incluyen habitualmente otras lenguas, entre las que, hasta bien entrado el siglo XIX, el latín ocupa un espacio preferente. De igual manera, la lexicografía bilingüe y plurilingüe de los orígenes está directamente relacionada con la traducción de textos y sigue el tracto sucesivo, es decir, los diccionarios se construyen sobre la base de diccionarios ya existentes. Así mismo, la lexicografía de esta combinación lingüística refleja la situación sociolingüística de las dos lenguas y en cierto modo podemos considerar 
que la lexicografía de los siglos XVI a XIX muestra de los altibajos de la lengua catalana: desde el esplendor del siglo XV, pasando por la decadencia representada por los siglos XVI al XVIII -caracterizados por la poca producción propia-, hasta el resurgimiento de la segunda mitad del siglo XIX.

La historia de la lexicografía bilingüe y plurilingüe entre el castellano y el catalán no habría sido la misma sin la aportación fundamental del Lexicon latín-español de Elio Antonio de Nebrija. Su traducción al catalán representa un primer momento álgido de la lexicografía catalana y puede ser considerada el antecedente inmediato de la lexicografía bilingüe y plurilingüe. Por supuesto, se trata más bien de una 'lexicografía diferida', pues las dos versiones (castellano y catalán) jamás se presentaron en una sola obra.

Deberemos esperar a principios del siglo XIX para encontrar el gran avance de la lexicografía entre el castellano y el catalán. La publicación en 1839 de la obra de Pere Labernia, el Diccionari de la llengua catalana ab la correspondencia castellana y llatina, y unos años más tarde el Diccionario de la lengua castellana con las correspondencias catalana y latina singulariza la lexicografía de esta combinación. Con todas sus limitaciones, el Labernia constituye el primer diccionario de entidad, bidireccional, completo y complejo del que dispone esta combinación lingüística. Su importancia, tanto desde el punto de vista de la técnica lexicográfica utilizada, como desde el punto de vista de la incidencia que tuvo en obras lexicográficas posteriores, lo hacen merecedor de una descripción detallada.

La segunda mitad del siglo XIX representa para el catalán un resurgimiento destacable que se refleja en la diversidad y multiplicidad de repertorios bilingües en los que el catalán y el castellano se tratan de forma conjunta. La auténtica producción de diccionarios bilingües castellano-catalán, no obstante, no se desarrollará hasta bien entrado el siglo XX.

La historia de la lexicografía bilingüe entre el castellano y el catalán está bien documentada gracias a diversas síntesis históricas, entre las que destacan la Gramàtica $i$ lexicografia catalanes: síntesi històrica, de Albert Rico y Joan Solà, de 1995, y la completa obra de Germà Colon y Amadeu J. Soberanas, Panorama de la lexicografia catalana, editada en Barcelona en 1986. Sus autores repasan las distintas manifestaciones lexicográficas, desde el siglo $\mathrm{X}$ con las primeras glosas de los textos latinos y de las gramáticas escolares que incluyen alguna aclaración en catalán, y llegan hasta 1932, en que aparece el primer volumen del Diccionari català-valencià-balear de Antoni M. Alcover y Francesc de B. Moll, y se publica el Diccionari de la llengua catalana de Pompeu Fabra. La obra de Colon y Soberanas tiene como objetivo presentar un panorama de la lexicografía catalana a lo largo del tiempo y es a nuestro juicio la más completa obra de referencia sobre la lexicografía histórica del catalán. Incluye, por supuesto, las referencias correspondientes a la lexicografía bilingüe del castellano con el catalán, y a ellas nos referiremos en las páginas siguientes, páginas que tienen por objetivo describir el panorama de la lexicografía bilingüe entre el catalán y el castellano a lo largo de los siglos XVI a XIX, con una especial dedicación al Diccionari de Pere Labernia, precursor de una auténtica lexicografía bilingüe moderna. 


\section{LOS INICIOS DE LA LEXICOGRAFÍA ENTRE EL CASTELlaNo Y EL CATALÁN: EL SIGLO XV}

Colón y Soberanas (1986: 30) apuntan al siglo XV como inicio de las manifestaciones lingüísticas en las que el español y el catalán empiezan a convivir en repertorios léxicos. En concreto, se refieren al Vocabularium scholare latinum, cuaderno de notas en el que un estudiante había apuntado la equivalencia en castellano y a menudo también en catalán de las palabras latinas. A partir de aquí, son numerosas las obras que, sin estar todavía especialmente concebidas como repertorios lexicográficos, incluyen el catalán y el castellano en sus páginas.

Con anterioridad al siglo $\mathrm{XV}$, la historia de la lexicografía catalana tiene un grado de autonomía destacable desde los siglos X y XI. Sus muestras más representativas se expresan en forma de glosas, rimarios, grammaticae proverbiandi y los ejemplos medievales de explicación de voces.

Las glosas, que son aclaraciones de voces oscuras por medio de sinónimos o perífrasis más o menos largas, suelen partir de los textos latinos y se redactan bien en latín, bien en lengua vulgar. Las primeras glosas catalanas aparecen durante los siglos X y XI, en latín, y como explicación de voces oscuras. En catalán aparecen hacia 1200. El primer glosario alfabético con equivalencias catalanas está fechado en el siglo XIV y está formado por una lista de 300 lexemas aclarados en latín. Los rimarios, por su parte, aparecen durante el siglo XIV y consisten en agrupaciones de palabras según su terminación. Los dos más representativos son el Llibre de concordances, de Jaume March, i el Torsimany, de Lluís d'Averçó. Las grammaticae proverbiandi son listas de verbos latinos con su equivalente vulgar, algunos en la variedad valenciana. Destacan el manuscrito 8950 de la Biblioteca Nacional, titulado Grammatica proverbiandi, obra destinada a la enseñanza del latín en las escuelas, o el manuscrito 43 de la Biblioteca Pública de Tarragona. Los ejemplos medievales de explicación de voces aparecen durante los siglos XIV y XV en tablas explicativas, habitualmente en latín, de los tecnicismos de las obras a las que se adjuntan. Son destacables los casos del Ars amativa, de Ramon Llull, y el De regimine principium de Gil de Roma.

Los antecedentes de la lexicografía bilingüe catalana incluyen obras concretas de mayor entidad, tales como el Comprehensorium, de Johanes, considerado el primer diccionario catalán por las palabras en vulgar que contiene; el texto es latino e incluye una equivalencia en occitano. Sigue el Liber elegantiarum, de Joan Esteve, aparecido en 1489 en Venecia, y que es considerado uno de los primeros repertorios que supera los simples glosarios y las listas de equivalencias. En él, el autor se propone ofrecer la equivalencia latina de voces catalanas. La obra está ordenada alfabéticamente.

A su lado, la lexicografía bilingüe se desarrolla en combinación con otras lenguas, como el alemán. Es obra pionera el Vocabolari molt profitós per aprendre lo Catalan Alamany $i$ lo Alamany Catalan, publicado en 1502 en Perpiñán. En realidad, la obra es una adaptación de uno de los vocabularios alemán-italiano que circulaban por Europa a finales del siglo $\mathrm{XV}$. La ordenación de las voces tiene tendencia sistemática (las voces se agrupan por áreas 
temática (la casa, los animales, la guerra, la enfermedad, etc.). Consta de unas 2.700 entradas.

\section{El LATín, LENGUA de ACOMPAÑAMIENTO DE LA LEXICOGRAFíA BILINGÜE Y PLURILINGÜE ENTRE EL CASTELLANO Y EL CATALÁN}

El primer repertorio lexicográfico que se documenta entre el castellano y el catalán está relacionado con la traducción de la obra de Ausiàs March al castellano. Baltasar de Romaní publicó en 1539 las obras del poeta en una edición bilingüe; en 1553, el mismo autor publicó en Sevilla la traducción castellana de la obra de March. Dos años más tarde, en 1555, Juan de Resa, capellán del rey, mandó a la imprenta en Valladolid la obra de Ausiàs March, en catalán, acompañada solamente de un vocabulario con la explicación en castellano. Juan de Resa, pues, ofrece el primer léxico entre las dos lenguas peninsulares. El valor lexicográfico de esta obra, según Colón y Soberanas (1986: 81) se considera relativo, pues la técnica lexicográfica no es elaborada: no existe una lematización propiamente dicha, los lemas seleccionados se presentan en la forma con la que aparecen en los textos, la selección de la nomenclatura no es completa, contiene numerosas inexactitudes, etc. De todos modos, su valor es innegable aunque en palabras de Colón y Soberanas se considere una rareza bibliográfica.

La traducción de textos clásicos, como el griego la Materia mèdica de Dioscórides, realizada por Andrés Laguna hacia 1555 es otra muestra de la importancia de la traducción en la historia de la lexicografía entre el castellano y el catalán. En esta ocasión, Laguna acompañó el texto traducido del griego con denominaciones en griego, latín, árabe, castellano, catalán, portugués, italiano, francés y alemán. La obra es importante para la lexicografía catalana porque algunas denominaciones representan las primeras manifestaciones en catalán. La obra del segoviano Laguna fue aprovechada por el aragonés Lorenzo Palmireno para realizar su Vocabulario del humanista (1569), un texto con finalidad didáctica, para enseñar latín a sus alumnos. El libro debía estar dividido en 9 "abecedarios" (dedicados respectivamente a los pájaros, peces, hierbas, animales cuadrúpedos, monedas, metales y piedras preciosas, palabras y frases, y palabras antiguas). Para la lexicografía catalana son importantes los tres primeros abecedarios, en los que se encuentran de forma desigual equivalencias, frases y explicaciones, preferentemente en castellano, pero complementados con la forma en catalán. Las formas en catalán de la sección de botánica, por ejemplo, fueron extraídas directamente de la obra de Laguna. La obra de Palmireno se reeditó en Barcelona en 1575.

El mismo año, Onofre Pou, discípulo de Palmireno y catalán de Girona, publica su Thesaurus Puerilis. Tenía la misma finalidad que la obra de Palmireno (que no tuvo el éxito esperado) pero en catalán: enseñar latín a los catalanes y en su lengua. La obra tuvo un gran éxito en la época y hacia 1615 se editó la traducción castellana de la obra (traducción atribuida al gramático valenciano Bernabé Soler). El Thesaurus puerilis es un repertorio léxico destinado a valencianos y catalanes con la correspondencia en su vulgar que tienen como finalidad principal la enseñanza del latín. El repertorio está organizado según un orden conceptual, a modo de un diccionario ideológico. Éste es su mérito lexicográfico 
principal, pero es también una muestra más de una lexicografía incipiente que podríamos calificar de diferida.

\section{EL NEBRIJA CATALÁN, PRIMER MOMENTO ÁLGIDO DE LA LEXICOGRAFÍA CATALANA}

La historia de la lexicografía bilingüe español-catalán tiene su primer momento álgido con la traducción del diccionario Nebrija al catalán. El denominado Nebrija catalán constituye la primera gran innovación lexicográfica del panorama lexicográfico del momento. Su primera edición se consiguió en 1507 (y de él constan otras tres estampaciones en 1522,1560 y 1585 con variaciones respecto a la primera) $)^{1}$. La obra es una adaptación al catalán del Lexicon latín-español de Elio Antonio de Nebrija de 1492. El diccionario fue traducido por el monje agustino Gabriel Busa, de forma que a principios del siglo XVI los lectores catalanes tuvieron acceso al primer diccionario latín-catalán, ordenado alfabéticamente a partir del español.

La adaptación del diccionario original se conoció como el Nebrija catalán y aunque no se trata de un diccionario bilingüe en el sentido actual, debemos considerarlo una muestra relevante de la lexicografía bilingüe de las dos lenguas, obviamente en forma diferida, pues no era objetivo del diccionario contraponer lexicográficamente las dos lenguas en un mismo repertorio.

Colón y Soberanas (1986: 66) ofrecen algunos ejemplos que muestran el resultado de la traducción, que ilustran claramente la dependencia de la traducción catalana:

\begin{tabular}{|l|l|}
\hline Nebrija, Lexicon, Salamanca, 1492 & Nebrija, Vocabularius, trad. por G. Busa, Barcelona, 1507 \\
\hline Caballus.i. por el cavallo arrocinado & caballus.i. lo vauall de sella e albarda. \\
Caballinus.a.um. por cosa deste cavallo & Caballinus.a.um. per cosa daquest cauall. \\
Cabille.es. por una fuente en mesopotamia & Cabille.es vna font en mensopotamia [sic] \\
Caca.e. hija de vulcano e ermana de caco & Caca.e. filla de vulcano e germana de caco. \\
Cacabus.i. por lacaldera para cozer & Cacabus.i. la caldera pera coure. \\
\hline
\end{tabular}

\section{LA PRODUCCIÓN LIMITADA DE LOS SIGLOS XVII Y XVIII}

Durante el siglo XVII la producción de repertorios distingue claramente el catalán del castellano. La producción lexicográfica catalana se restringe a los diccionarios que tienen

\footnotetext{
${ }^{1}$ Según Colón y Soberanas (1986: 74) las variaciones consisten en añadidos en las definiciones, explicaciones en latín cuando el original proporcionaba una equivalencia vulgar, soluciones léxicas distintas de las dadas por Busa y supresión de lemas respecto a la estampación original.
} 
como finalidad el aprendizaje del latín por parte de estudiantes catalanes, aunque en la mayoría de los casos se trata de traducciones de diccionarios castellanos. Los tres diccionarios más representativos son el Diccionari llatí-català, de Antoni Font, el Thesaurus de Pere Torra y el Gazophylacium de Joan Lacavalleria i Dulach. La obra de Font parece ser una adaptación del Thesaurus verborum ac phrasium latín-castellano del jesuita segoviano Bartolomé Bravo (Colon y Soberanas 1986: 107), cuya primera edición está fechada supuestamente en Pamplona, en 1590. La obra de Font apareció como Fons verborum et phrasium, en Barcelona y en 1637. A su vez, la obra de Pere Torra fue una nueva adaptación de la obra de Bravo, publicada en 1640. Antoni Lacavalleria publicó en 1696 el Gazophylacium catalano-latinum, dictiones phrasibus illustratas, ordine literario comprehendens cui subjicitur irregularium verborum elenchus. El mismo Lacavalleria menciona los diccionarios de Font y Torra, pero los considera demasiado eruditos y reducidos (Colon y Soberanas 1986: 111). A diferencia de los mencionados, el diccionario de Lacavalleria no incluye el castellano, sino el catalán y el francés.

El castellano mantiene su presencia, pero en obras plurilingües como el Vocabulario de seis lenguas, publicado por Fra Miquel Agustí, prior del templo de la ciudad de Perpiñán, en 1617, que presenta el léxico ordenado alfabéticamente a partir de la voz castellana, con equivalentes en catalán, latín, portugués, italiano y francés.

A lo largo del siglo XVIII, aunque la lengua catalana escrita no había recuperado todavía su estatus, existen varias muestras de una ya incipiente lexicografía bilingüe castellano-catalán: el Vocabulari català-castellà de mots antics, de Fra Manuel Marià Ribera, el Prontuario orthologi-gráphico trilingüe en que se enseña a pronunciar, escribir y letrear correctamente en latín, castellano y catalán; con una idia-graphia o arte de escribir en secreto o con llave idia-gráphica de Marià Soldevila y publicado en Barcelona en 1743. Siguen las Instruccions per la ensenyança de minyons de Baldiri i Reixach, publicado en Girona en 1749 (que pretende recoger alfabéticamente las palabras castellanas más alejadas del catalán y de más difícil comprensión para los niños que aprendían la lengua).

Destaca en este siglo el interés por el aprendizaje de otras lenguas, como el francés, tradición iniciada por Lacavalleria en el siglo anterior. De esta época destaca el Promtuario trilingue en el que se manifiestan con toda claridad todas las vozes que generalmente sirven para el Comercio politico y sociable en los tres idiomas cathalán, castellano y francés, a fin de que los pocos instruidos en algunos de los dos primeros entren con menos dificultad a la inteligencia del tercero. Josep Broch, clérigo y maestro, lo publicó en 1771.

Durante este siglo, la actividad lexicográfica bilingüe más importante fue la desarrollada por Carles Ros, notario de Valencia. Publicó el Breve diccionario valencianocastellano, en 1739; y el Diccionario valenciano-castellano, de 1764, cuya función principal era que los valencianos aprendieran bien el castellano, a la vez que su lengua materna.

Para el mallorquín, la obra más destacable del siglo XVIII está constituida por el Vocabulari mallorquí-castellà, compuesto por Fra Antoni Oliver, franciscano. La obra sigue el repertorio del diccionario de la Academia, establece una lista ordenada 
alfabéticamente de las voces mallorquinas de las que ofrece equivalentes en castellano y en latín, sin definiciones.

El vocabulario catalán-castellano de palabras antiguas, de Antoni de Capmany, formaba parte de una colección de más de 300 documentos medievales en lenguas distintas (latín, catalán, castellano, francés y griego). Al final de los documentos, publicados entre 1779 y 1792, se incluye un "Vocabulario de algunas palabras del latín de esta colección traducidas en castellano para mayor inteligencia de sus instrumentos" (Colon y Soberanas 1986: 127). El mismo autor publicó en 1791 un glosario catalán-castellano con la traducción castellana del Llibre del Consolat de Mar. El texto incluye un "vocabulario de las palabras catalanas más difíciles del Libro del Consulado", con la equivalencia castellana, y además un "glosario castellano de los vocablos náuticos y mercantiles contenidos en esta traducción" (Colon y Soberanas 1986: 127).

A partir de la publicación del Diccionario de la lengua castellana de la Real Academia Española (Madrid, 1726-1739), surgió en Cataluña la necesidad de disponer de un diccionario parecido. Los esfuerzos se dirigieron a que la Acadèmia de les Bones Lletres se hiciera cargo del proyecto. Pero con la publicación de la real cédula de Carlos III, de 23 de junio de 1768, se inició el conocido proceso de castellanización comenzando por el mandato que "la lengua vulgar en las Aulas no sea, aun para Cathaluña, otra que la Castellana" (Colon y Soberanas 1986: 129). Y para aprender la lengua castellana ninguna herramienta es mejor que un diccionario. Por ello, Josep Climent, obispo de Barcelona, se dirigió a la Academia para que se hiciera cargo del proyecto. La Academia acogió bien el proyecto en un primer momento, e incluso llegó a establecer las bases y el método lexicográfico que se debería seguir para producirlo. Para ello solicitó financiación en 1770 a Carlos III (con un texto que rezaba "al presente, se halla entendiendo en la formación de un diccionario trilingüe dezeado de los eruditos y cuya idea se persuade que ha de merecer vuestra real aceptación, es a saber: castellano, catalán y latino y catalán, castellano y latino a norma del de la Real Academia de la Lengua Española de essa corte, obra tan difícil y molesta como útil para propagar y extender en la Provincia, según vuestras reales intenciones, el idioma español y facilitar la inteligencia de una lengua que en otros tiempos lo fue de Corte, y en la que escribieron varias obras los reyes de Aragón y que se conservan en el día", citado por Colón y Soberanas 1986: 131). Desdichadamente, el proyecto nunca fructificó $^{2}$.

\section{El RESURGimiento de la leXicografía CATAlana: la RENAIXENÇA DEL SIGLO XIX}

En la mayoría de repertorios lexicográficos editados durante el siglo XIX el elemento común es el castellano. Se editan diccionarios catalanes, valencianos, mallorquines y menorquines, con correspondencia en castellano, y en este momento prácticamente

\footnotetext{
${ }^{2}$ Colón y Soberanas (1986: 133) lo atribuyen al factor humano (en la Academia no había ningún lexicógrafo con preparación adecuada), a la falta de dinero o por la dimisión forzada del obispo Climent en 1775.
} 
desaparece el latín, tercera lengua que había estado presente en la tradición lexicográfica hasta entonces.

La primera obra lexicográfica impresa durante el siglo XIX es el Diccionario cataláncastellano-latino, publicado por Joaquim Esteve, Josep Bellvitges y Antoni Juglà, y redactado por Fèlix Amat de Palou. El diccionario puede ser considerado, en palabras de Colon y Soberanas (1986: 144) como la materialización de las tentativas realizadas en Barcelona a partir de la publicación del diccionario de la Academia. El diccionario de Amat ocupará el espacio lexicográfico de la pre Renaixença. El autor elaboró originalmente un diccionario bilingüe castellano-catalán, pero la versión publicada incluyó además las equivalencias en latín. La obra de Amat es la primera que tiene por objeto el estudio de la lengua catalana (los diccionarios de importancia anteriores, como los de Torras o Lacavalleria, tenían como objetivo el estudio del latín). Amat tenía una voluntad recuperadora y busca la identidad catalana, explicada a partir de un interés por elaborar un diccionario lo más “completo y exacto" (Colon y Soberanas 1986: 148).

Siguiendo el diccionario de la Academia, algunas de las obras más representativas de esta época son el Diccionari castellà-català, de Fra Magí Ferrer, y también el Diccionario castellano-catalán, del mismo autor. Luego vendría el diccionario Labernia, diccionario de referencia del siglo XIX: el Diccionari de la llengua catalana ab la correspondencia castellana y llatina y el correspondiente Diccionario de la lengua castellana con las correspondencias catalana y latina, del que nos ocupamos más adelante.

El panorama de la lexicografía bilingüe y plurilingüe entre el castellano y el catalán no puede prescindir de la obra contemporánea del Labernia. Nos referimos al Diccionari catalá-castellá-llatí-francès-italià, publicado en 1839 por una sociedad de catalanes, sociedad formada por Salvador Estrada, Antoni Matamala, Ferran Patxot, Joan Cortada y Lluís Bordas. Las estructuras del diccionario mantienen gran parecido con las del Labernia, coincidencia poco original, pues los dos se basan en el modelo común del diccionario de la Academia. Cada artículo del quintilingüe contiene el lema, una indicación gramatical, la definición en catalán y los equivalentes en castellano, latín, francés e italiano. El diccionario tiene una versión castellana en el Diccionario castellano-catalán-latinofrancés-italiano, editado en tres volúmenes en Barcelona, en 1845 y 1848.

En 1851 se imprimió en Barcelona una obra de baja calidad (en palabras de Colon y Soberanas 1986: 164) pero que sorprendentemente tuvo éxito y difusión: el Diccionario manual ó vocabulario completo de las lenguas catalana-castellana, del naturalista Santiago Àngel Saura. En 1852 se publicó el diccionario complementario Diccionario manual ó vocabulario completo de las lenguas castellana-catalana. De estas obras existen numerosas reediciones incluso en el siglo XX.

En esta época, Valencia se convierte en la sede de las principales impresiones de diccionarios durante este siglo, como muestran entre otras el Ensayo de un Diccionario valenciano-castellano, de Lluís Lamarca (lista de aproximadamente mil palabras catalanas con su equivalencia castellana); Miscelánea de Miquel Rosanes (obra de unas mil seiscientas entradas en catalán con equivalencia en castellano); el Vocabulari valenciàcastellà de Josep M. Cabrera (cerca de dos mil entradas, ordenadas alfabéticamente). Uno de los diccionarios valencianos de más prestigio fue el valenciano-castellano de Josep 
Escrig, cuya primera edición apareció en 1851. El diccionario contiene cerca de 90.000 entradas, aunque en términos de Colon y Soberanas su calidad lingüística sea dudosa; Joaquim Martí i Gadea es el autor del Novísimo diccionario general valenciano-castellano, publicado en 1891, que contiene un corpus reflejado en 1976 páginas. La calidad del material, también según Colon y Soberanas, es dudosa.

Las Islas Baleares son así mismo un lugar de actividad lexicográfica importante entre el catalán y el castellano durante el siglo XIX: el Diccionari mallorquí-castellà, publicado en 1840, de Pere Antoni Figuera (recoge palabras mallorquinas definidas en catalán y seguidas de la equivalencia castellana); en 1869, Josep Hospitaler i Caballer publicó el Vocabulario castellano-menorquín y vice-versa. Se trata de un repertorio léxico agrupado temáticamente a partir del castellano; el objetivo de este diccionario es, como el de la mayoría de diccionarios de esta época, difundir el conocimiento del castellano. Cabe destacar también el Vocabulario menorquín-castellano, de Joan Benejam, de 1885.

En la segunda mitad del siglo XIX hemos de reconocer el valor de las obras de dos eruditos catalanes: Aguiló y Balari ${ }^{3}$, que otorgan a la lexicografía catalana un carácter científico desconocido hasta el momento. De acuerdo con los métodos históricocomparativos de la lingüística, analizan la lengua catalana antigua, realizan una gran tarea de recogida de materiales y pretenden revitalizar dichos materiales para contribuir a la recuperación de la lengua catalana.

El primero, Marià Aguiló, recopiló los materiales que darían lugar al diccionario que lleva su nombre, el Diccionari Aguiló, editado entre 1914 y 1934 en 8 volúmenes y por Pompeu Fabra y Manuel de Montoliu. Aunque se trata de un diccionario monolingüe catalán, en algunos casos las definiciones se sustituyen por equivalentes en castellano. El segundo, Josep Balari, compiló el Diccionari Balari que es, como el de Aguiló, un repertorio póstumo de los materiales recopilados por el autor, publicado a partir de 1926 en fascículos, e interrumpida en 1936 en la letra G. El diccionario parte de documentación antigua y contemporánea; en el prólogo ya se hace constar que la obra será de interés para conocer el equivalente exacto en castellano de los vocablos catalanes y que este punto es uno de los rasgos distintivos del diccionario en relación con el repertorio de Aguiló.

\section{El DiCCIONARI DE LA LLENGUA CATALANA AB LA CORRESPONDENCIA CASTELLANA Y LLATINA, Y EL DICCIONARIO DE LA LENGUA CASTELLANA CON Las Correspondencias Catalana Y latina, de PERE LABERNIA}

El diccionario de Labernia es, como hemos mencionado, un referente en la lexicografía bilingüe y plurilingüe entre el castellano y el catalán por varios motivos. En primer lugar, porque el léxico de la Renaixença que mantuvo un cierto prestigio y autoridad hasta la

\footnotetext{
${ }^{3}$ Dos son los eruditos que recopilaron materiales para la publicación de sendos diccionarios en los que el castellano tuvo algún lugar. La historia de la lexicografía catalana suele incluir entre los eruditos que trabajaron en cuestiones histórico-filológicas a Julià-Bernat Alart, quien elaboró el Essai de dictionnaire historique de la langue catalane, que no consideramos aquí por no incluir el castellano entre las indicaciones microestructurales.
} 
publicación del Diccionari de la llengua catalana de Pompeu Fabra, ya en el siglo XX, fue precisamente el que contenía el diccionario de Labernia. Hay que considerar, además, que el Labernia fue el único diccionario que tuvo cierta aceptación general. Es el diccionario de base de la lexicografía actual y su influencia se extendió a los diccionarios de referencia del siglo XX, tanto monolingües como bilingües (en este sentido destaca su influencia en las fuentes del Diccionari català-valencià-balear de Antoni M. Alcover). Sobran pues motivos para dedicar un espacio preferente al diccionario Labernia.

El primer volumen de la obra fue publicado en 1839 y el segundo, en 1840, tras 18 años de 'trabajo intenso' (así lo expresa el autor en el prólogo de la versión catalán-castellano). Y el diccionario castellano-catalán se editó, también en dos volúmenes, en 1844 y 1848 . La primera intención del diccionario catalán-castellano se recoge en el prólogo: "era menester estudiar al mateix temps la índole de nostre hermós é incomparable idioma nacional, que tan ventatjosament se ha generalisat entre nosaltres desde que formam part de la gran familia espanyola, y buscar las vertaderas correspondencias entre los vocables y frases de dos idomas desiguals en veritat, si se aten á la disparitat que hi ha entre una llengua que quedá com adormida fa tres sigles, y altra que ha estat posteriorment cultivada, $\mathrm{y}$ ha seguit los progressos de la civilisació". Su primera intención con la versión castellano-catalán fue dar, a través del diccionario "á nuestra lengua patria mayor número de correspondencias con las lenguas vivas y muertas, que con preferencia nos interesan, como son, á mas del castellano y latin, el francés, ingles, italiano y griego, y no le hubieran faltado medios para conseguirlo: pero la consideración de que el verdadero objeto de un diccionario de la lengua y lo que mas desean los amantes de la nuestra es mayor cúmulo de voces, frases y modismos en su equivalencia con la lengua nacional, le decidió á seguir en esta parte el ejemplo de la sabia y respetable Academia española, la cual en todas las ediciones del diccionario de la lengua castellana se limita unicamente á su correspondencia con la lengua madre, que es la latina".

La obra tuvo tres ediciones más, revisadas y corregidas, en 1864-1865 por Lluís Tasso, en 1868 por los Hermanos Espasa y en 1888-1892 por Apel-les Mestres. El éxito del diccionario permitió que la editorial Salvat lo reeditara (aún sin constar Labernia como autor) con el título Diccionario de la lengua catalana ab la correspondencia castellana y una vez aceptadas las normas ortográficas del Institut d'Estudis catalans, otras ediciones con la denominación Diccionari enciclopèdic de la llengua catalana amb la correspondència castellana. Su última edición controlada fue en 1930-1936 en cuatro volúmenes.

Salvando las distancias temporales y metodológicas lógicas, el diccionario puede ser analizado desde el punto de vista metalexicográfico de la lexicografía bilingüe actual, asumiendo que su objetivo principal es contraponer lexicográficamente las unidades léxicas de dos lenguas entre las que existe equivalencia en el nivel léxico. En los parámetros lexicográficos de nuestro momento, digital y especializado, en cambio, el diccionario de Labernia seguramente sería considerado más un diccionario monolingüe con equivalencias (Rafel 2005: 51) que no un auténtico diccionario bilingüe, pero los parámetros del siglo XIX le atribuyen un valor bilingüe superior al que le otorgaría la metalexicografía del siglo XXI. 
El diccionario no incluye información sobre las funciones lexicográficas para las que se concibe. Este extremo no sorprende, aunque el prólogo del diccionario castellano-catalán tiene en cuenta de forma explícita la comparación entre lenguas (y así se expresa el autor cuando advierte que "La mayor falta que puede presentar un buen diccionario es que se ofrezca palabra que no lleve correspondencia en las lenguas que se comparan, y que falten en él las voces con que deben quedar denominados los objetos que sirven á los usos de la vida, así moral como físicamente hablando, y esto ha sido lo que he procurado evitar cuidadosamente cualquiera que sea el parecer de los que así no piensan sobre este punto").

Desde el punto de vista hiperestructural, hay que distinguir los dos volúmenes cataláncastellano del castellano-catalán, pues no se configuran de forma idéntica. La versión catalán-castellano está formada por dos volúmenes (A-G, J-W), e incluye una parte inicial, constituida a su vez por los textos de presentación y de orientación (en concreto, una dedicatoria, un prólogo y la lista de las abreviaturas usadas en el diccionario); le sigue el cuerpo, formado por 988 páginas el primer volumen y 990 el segundo, a doble columna; el primer volumen concluye con una parte final, formada por un suplemento final de 50 páginas a doble columna (aproximadamente 1.200 artículos más ordenados alfabéticamente), un bloque dedicado a la ortografía (formado por 7 páginas con información sobre las letras y sobre reglas de puntuación), así como una página con la fe de erratas de los tomos I y II.

La versión castellano-catalán está formada también por dos volúmenes (A-G, J-W) e incluye la parte inicial, con dos textos de presentación y orientación: una dedicatoria, traducida de la versión catalán-castellano, más un prólogo. Le sigue una "Nota de los autores cuyas iniciales van puestas al pié de cada artículo ó acepción nuevamente adoptada, para darle el crédito y autoridad correspondiente" (se incluyen referencias a 79 fuentes). La nota va seguida de una explicación de las abreviaturas usadas; la parte inicial finaliza con una advertencia sobre la forma de lematización de las unidades fraseológicas. El cuerpo del diccionario se desarrolla a lo largo de las 971 páginas del primer volumen y de las 1020 páginas del segundo, a doble columna. El diccionario finaliza sin información complementaria.

Sobre los textos de presentación, cabe destacar que los prólogos de las dos versiones son distintos. En el catalán-castellano se ofrece una aproximación a las fuentes de consulta, a los objetivos principales de la obra y a la (moderna y hasta cierto punto envidiable) forma de construcción de los artículos: "Se dèu també advertir, que en orde á las diferents parts que componen cada article se colloca primerament lo article ab totas sas diversas accepcions separadas ab dos rallas verticals; en seguida aquellas locucions, frases ó refrans que comensan per lo mateix article ques defineix, seguint lo orde alfabétich; y desprès tots los noms, així substantius com adjectius y modos adverbials ques derivan ó se componen de qualsevol modo, de qualitat ó cosa que puga tenir relació ab lo article definit, procurant sempre aténdrer á la paraula de la major importancia de la frase, ja sia nom ó verb ó qualsevol altra part de la oració, y no limitantme en aquest punt á altre método que á la major facilitat de trobar aquells modismes ó locucions".

Por su parte, en el prólogo de la versión castellano-catalán se incide en la necesidad de un diccionario de estas características especialmente para el sector público: "Pero en donde 
se notaba mas ostensiblemente, y en donde se hacia cada vez mas trascendental esta falta era en los instrumentos de las oficinas públicas, y en las obras que respectan á las ciencias y á las artes". Así mismo, esta versión destaca el hecho que "El diccionario que doy á luz con mas de 8000 voces que no se hallan continuadas en el de la Academia". Para dar autoridad a estas incorporaciones, Labernia incluye la ya mencionada "Nota" que destaca las 79 fuentes complementarias consultadas (y que toman en consideración desde la "Academia Española", al "Diccionario Marítimo redactado por orden de Fernando VII, en 1831", "D. Luís Megía", "Santa Teresa" o el mismo "P. Esteban de Terreros", entre otros).

Como hemos mencionado, no podemos considerar que se trate de un diccionario bidireccional catalán/castellano a la luz de los parámetros del siglo XXI, pero constatamos que las dos direcciones son relativamente autónomas y no son una simple reversión una de otra. Ciertamente se observan artículos idénticos, en los que solamente cambia la metalengua, pero son claras las muestras de autonomía de las dos direcciones. Una revisión parcial de los artículos permite afirmar que los dos sentidos tienden a una adaptación ejemplar de los elementos culturales de cada lengua, lematizan las formas predecibles de los signos lemáticos, incluyen una definición de tipo enciclopédica, marcada ideológicamente, y en los dos sentidos destaca el tratamiento ejemplar de los equivalentes funcionales.

Las dos versiones se diferencian por cuestiones más bien gráficas y, en general, la versión castellano-catalán trata con mayor detalle las voces que el sentido cataláncastellano, identifica la fuente de algunos lemas de forma explícita, e incluye una cantidad claramente superior de marcas temáticas. Por su parte, la versión catalán-castellano destaca por un tratamiento excepcionalmente riguroso de la fraseología.

Ilustramos a continuación con un poco más de detalle algunos rasgos principales del diccionario, a saber, las cuestiones formales más destacadas, la adecuación del diccionario al destinatario preferente, los rasgos esenciales de la nomenclatura principal y los rasgos más destacados del tratamiento de la definición y la equivalencia.

\section{Cuestiones formales}

1) Se tiende a tratar con mayor detalle las voces en el sentido castellano-catalán:

\begin{tabular}{|c|c|}
\hline Catalán-castellano & Castellano-catalán \\
\hline $\begin{array}{l}\text { CITA. f. Senyal ó avís del lloch y temps pera } \\
\text { véurerse ó parlarse alguna persona ab altra. Cita. } \\
\text { Conditio, citatio, convenio, nis. \# Referencia á } \\
\text { alguna lley, autoritat, ó altre instrument pera } \\
\text { comprobar lo ques diu. Cita, Testimonium, ii, } \\
\text { auctoritas, atis. }\end{array}$ & $\begin{array}{l}\text { CITA. f. Señalamiento, asignacion de dia, } \\
\text { hora y lugar para verse y hablarse. Cita. Diei aut } \\
\text { loci dictio quò aliqui conventuri sunt } \| \text { La nota de } \\
\text { ley, doctrina, autoridad ó instrumento que se alega } \\
\text { para prueba. Citació de subasta. Citatorium. }\end{array}$ \\
\hline \begin{tabular}{l}
\multicolumn{2}{c}{ ADVOCAT, DA. P.p. Abogado. Advocatus. } \\
|| Profesor de jurisprudencia. Abogado, \\
jurisconsulto. Causidicus, advocatus, patronus, i, \\
causarum actor. $\quad$ met. Intercesor. Abogado,
\end{tabular} & $\begin{array}{l}\text { ABOGADO, A. p.p. Advocat. } \| \text { m. Profesor } \\
\text { de jurisprudencia, que con título legítimo defiende } \\
\text { en juicio. Advocat. Causarum patronus. \| met. } \\
\text { Intercesor, medianero. Advocat, medianer. }\end{array}$ \\
\hline
\end{tabular}




\begin{tabular}{|c|l|}
$\begin{array}{c}\text { intercesor, medianero, protector, patrono. } \\
\text { Advocatus, patronus, i, deprecator, protector, is. }\end{array}$ & Patronus, i. \\
\hline $\begin{array}{c}\text { GURRUMÍ. m.fam. Marit massa } \\
\text { condescendent. Gurrumino. Uxorius, ii. }\end{array}$ & $\begin{array}{l}\text { GURRUMINO. m.fam. El marido que } \\
\text { contempla con exceso á su mujer. Femellut, joan } \\
\text { doneta. Uxoris maritus. }\end{array}$ \\
\hline $\begin{array}{c}\text { ZUTANO. m. Veu inventada pera citar á algú } \\
\text { sens expressar son nom. Zutano. Quidam, alter. }\end{array}$ & $\begin{array}{l}\text { ZUTANO. A. mf. Voz inventada para citar á } \\
\text { alguno ó suplir su nombre, cuando este se ignora } \\
\text { ó no se quiere expresar: especialmente se usa } \\
\text { como correlativo de fulano cuando se habla de } \\
\text { dos ó de mas, y hablando del segundo y los demás } \\
\text { se dice ZUTANO. Zutano, sutano. Quidam, alter. }\end{array}$ \\
\hline
\end{tabular}

2) Las ocasiones en las que la situación se invierte suelen estar relacionadas con el tratamiento de la fraseología, más rico en la versión catalán-castellano:

\begin{tabular}{|l|l|}
\hline \multicolumn{1}{|c|}{ Catalán-castellano } & \multicolumn{1}{|c|}{ Castellano-catalán } \\
\hline ii. JUNY. m. Lo sisé mes del any. Junio. Junius, & $\begin{array}{c}\text { JUNIO. m. El sexto mes del año, que era } \\
\text { cuarto entre los antiguos romanos, y consta de } \\
\text { treinta dias. Juny. Junius. }\end{array}$ \\
$\begin{array}{l}\text { EN LO JUNY LA FALS EN PUNY. ref. Denota que de juny se déu preparar pera segar. } \\
\text { Cuando canta la abubilla, deja el buey y toma la } \\
\text { gavilla. Maturae junio falce secantur aristae. }\end{array}$ & \\
\hline
\end{tabular}

\section{Adecuación al destinatario preferente}

3) La adecuación de cada versión se manifiesta en la pertenencia de la información que contienen los artículos, perfectamente adaptados a la cultura de la lengua de origen del diccionario (catalán o castellano). Obsérvese la diferencia de tratamiento en los ejemplos relacionados con los tipos de testamento, pertinentes para el ordenamiento jurídico catalán:

\begin{tabular}{|c|l|}
\hline \multicolumn{1}{|c|}{ Catalán-castellano } & \multicolumn{1}{c|}{ Castellano-catalán } \\
\hline $\begin{array}{c}\text { NOTARI. m. Escribá públich. Escribano, } \\
\text { notario. Notarius, ii. \| ACTUARI. }\end{array}$ & $\begin{array}{l}\text { NOTARIO. m. Escribano público. Notari. } \\
\text { Notarius, tabellio. \| En lo antiguo el que escribia } \\
\text { con abreviaturas. Hoy se distinguen de los } \\
\text { escribanos en que estos entienden en los negocios } \\
\text { seglares, y los NOTARIOS en los eclesiasticos. } \\
\text { Notari. Notarius. \| AMANUENSE. } \| \text { DE CAJA. p. } \\
\text { Ar. Notario del número de Zaragoza. Notari de } \\
\text { número. Notarius. \| MAYOR. El principal ó gefe en } \\
\text { la notaría. Notari major. Notarius primas. }\end{array}$ \\
\hline
\end{tabular}




\section{[TESTAMENT]}

TESTAMENT CLOS. Lo cubert ab una carpeta, sobre la qual firma lo testador, si sab, y sino altre en nom de ell, y dos testimonis, en presencia dels quals lo entrega al notari. Testamento cerrado. Clausum, secretum testamentum.

TESTAMENT MILITAR. Lo que fa lo soldat en campanya, sens altra solemnitat que dos testimonis ó una simple escriptura de sa propia ma; pero de ninguna manera será válit aquest testament, no sent fet en campanya. Testamento militar. Militare testamentum.

TESTAMENT NUNCUPATIU. Aquell en que lo testador expressa de viva veu tota sa voluntat sobre lo hereu, llegats y altras disposicions. Antiguament en virtut de un privilegi que Pere III rey de Aragó concedí a Barcelona y sos ciutadans, podia lo notari fer lo testament estant sol ab lo testador, y despres de fet cridaba testimonis, davant dels quals deya, que ell habia notat lo testament del mateix testador, y valía com si lo haguessen oít los mateixos testimonis; peró en lo dia está revocat y abolit dit privilegi, y se fa en presencia de dos testimonis y un notari que fa una escriptura, suplint de aquest modo lo número de testimonis que de dret comú deurian sèr set. Testamento nuncupativo ó abierto. Testamentum nuncupativum.

TESTAMENT SAGRAMENTAL. Aquell en que un ciutadá de Barcelona declara y expressa sa última voluntat per escrit ó sols de paraula, presents los testimonis, encara que no haja notari, sia en terra ó en mar. Per esser válit aquest testament, se requireix quels testimonis, que assistíren á ell, dintre lo termini de sis mesos de estar en Barcelona juren ab las acostumadas solemnitats en la iglesia dels sants Just y Pastor de aquesta ciutat, sobre lo altar de sant Félix, vuy de santa Creu, que axí lo vegéren y oíren escríurer ó dir com se conté en la escriptura, ó com digué sols de paraula lo testador en sa última voluntat, com se llegeix en lo cap. 48. de las consuetuts de Barcelona, vulgarment ditas lo "Recognoverunt proceres." Testamento sacramental. Testamentum sacramentale.
ABIERTO. El que se otorga delante de tres testigos vecinos del lugar y un escribano público, y no habiendo escribano, ó siendo el otorgante ciego, de delante de cinco testigos vecinos del lugar. Testament nuncupatiu. Testamentum publicum. CERRADO. El que se entrega cerrado al escribano, firmado exteriormente por el testador y siete testigos vecinos del lugar en que se otorga con la fé del escribano. Testament clós. Testamentum obsignatum, secretum. soldado que se halla en guerra actual, sin otra solemnidad que probar su voluntad con dos testigos, ó por una simple escritura de su puño. Testament militar. Testamentum militare. \| NUNCUPATIVO, TESTAMENTO ABIERTO. $\|$ 


\section{Cuestiones de macroestructura}

4) Entre los aspectos relacionados con la macroestructura, destaca en primer lugar el tipo de unidades seleccionadas, que incluyen, además de la forma lemática típica, las derivadas más habituales:

\begin{tabular}{|c|c|}
\hline Catalán-castellano & Castellano-catalán \\
\hline CALUMNIA & EXAGERACION \\
CALUMNIADOR, A & EXAGERADOR, A \\
CALUMNIAL & EXAGERANTE \\
CALUMNIAR & EXAGERAR \\
CALUMNIAT, DA & EXAGERATIVAMENTE \\
CALUMNIÓS & EXAGERATIVO \\
CALUMNIOSAMENT & \\
\hline
\end{tabular}

5) Los lemas se suelen desarrollar de forma completa, pero en la versión castellanocatalán se incluyen ocasionalmente lemas agrupados:

CIRUELICA, LLA, TA. f. d. Pruneta. Tenue prunum.

CIRUELICO, LLO, TO. m. d. Prunereta. Parvus prunus.

6) Las unidades seleccionadas proceden de fuentes propias y ajenas. Para asegurar la fiabilidad del diccionario, la versión castellano-catalán menciona la fuente de origen:

Castellano-catalán

ENLECHUGUILLADO. A. adj. Que usa cuello de lechuguilla. Que porta coll crespat en forma de lletuga. Collari plicato et rugoso instructus, ornatus. A.

GUSBADUL. m. Cierta piedra fina. Gusbadul. Donde "T" se refiere a "Nuñez de Taboada". Lapis perpolitus. $\mathrm{T}$.

[GUSTO] HACERLE Á UNO EL GUSTO. Donde "M" se refiere a "Moratín". Hacerle el favor. Fer lo favor. Placere alicui. M. 
7) Las unidades sintagmáticas siguen un orden preciso. Las "Advertencias" del inicio del diccionario castellano-catalán aclaran los extremos siguientes:

\section{ADVERTENCIAS.}

1. a Un artículo que conste de dos ó mas voces entre las cuales haya un sustantivo, se buscará en el lugar alfabético correspondiente á este, y si hay mas de uno, en el del primero; escepto la palabra cosa por ser tan general.

2. ${ }^{a}$ Cuando en los artículos de esta clase no haya ningun sustantivo, se encontrará en el lugar que corresponda al verbo, si lo hay, ó en el del primero si hubiere mas de uno; pero si uno de estos fuese cualquiera de los auxiliares haber y ser, ó de los que hacen sus veces, como tener, ir, venir, no se considerarán como tales verbos, para evitar la repeticion que dificultaria hallar con brevedad lo que se busca.

3. ${ }^{\text {a }} \mathrm{Si}$ en el artículo no hubiese ningun sustantivo ni verbo, deberá buscarse aquel en el lugar que por órden alfabético corresponda al adjetivo, ó al primero de estos cuando haya mas de uno.

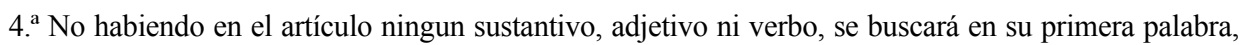
cualquiera que sea.

8) Las unidades fraseológicas reciben un tratamiento especialmente completo y complejo en el sentido catalán-castellano. Se incluyen unidades fraseológicas al final del artículo, y las unidades se glosan y se traducen con equivalentes funcionales en castellano y en latín. A diferencia, las unidades fraseológicas son prácticamente inexistentes en el sentido castellano-catalán:

[SANT] Á BON SANT HO ENCOMANA. fr. met. ab que se avisa á algú de que encarrega sos interessos á qui sol pérdrerlos ó destruhirlos. A buen santo te encomiendas; encomendar las ovejas al lobo [...] AL SANT QUE NO TINGAS DEVOCIÓ, NO LI FASSAS ORACIÓ. ref. Denota que qui no tè interés ab alguna persona, non fa cas o estimació particular. Al santo que no se tiene devocion, no se le hace oracion. [...] Á SANTS Y Á MINYONS NOLS PROMETAS QUE NOLS DONS. ref. Ensenya, ques déu cumplir tot lo ques promet. Ni al niño el bollo ni al santo el voto. [...] LI ESTÁ TANT BÈ COM Á UN SANT CRISTO DOS PISTOLAS. exp. fam. Se diu quant alguna cosa escau mal a qui la usa. Le está o le sienta como á la burra las arracadas. [...]

9) En cuanto al tratamiento formal de las unidades poliléxicas, el sentido cataláncastellano separa la fraseología del resto del artículo, mientras que el sentido castellanocatalán lo incluye a continuación de cada voz:

\begin{tabular}{|c|c|}
\hline Catalán-castellano & Castellano-catalán \\
\hline CITACIÓ.f. La acció de citar. Emplazamiento, & CITACIÓN. f. La accion de citar. Citació. In \\
\hline
\end{tabular}


citacion. Denuntiatio, conditio, vadatio, nis.

CITACIÓ DE REMAT. for. Notificació ó intima al deutor, de la venda ques va á fer de sos bens. Citacion de remate. Comperendinatio, nis. diem dictio || DE REMATE. for. Notificacion que se hace al deudor de la venta que se va á hacer de sus bienes. Citació de subasta. Citatorium.

10) Las voces marcadas por medio de abreviaturas son mucho más elaboradas en la versión castellano-catalán que en el sentido catalán-castellano, aunque el marcaje geográfico del catalán-castellano se detalla de forma superior (con referencias a "provincial de Andaluzía, Aragó, Asturias, Extremadura, Galicia, Murcia, Navarra").

A modo de ejemplo, las abreviaturas temáticas (A-E) comparadas:

\begin{tabular}{|c|c|}
\hline $\begin{array}{l}\text { Catalán- } \\
\text { castellano }\end{array}$ & $\begin{array}{l}\text { Castellano- } \\
\text { catalán }\end{array}$ \\
\hline Agricultura & $\begin{array}{l}\text { Agricultura } \\
\text { Alfarería } \\
\text { Albañilería } \\
\text { Albeiteria }\end{array}$ \\
\hline Álgebra & Álgebra \\
\hline Anatomía & Anatomía \\
\hline Aritmética & Aritmética \\
\hline Arquitectura & Arquitectura \\
\hline Artilleria & Artillería \\
\hline Astrologia & Astronoma [sic] \\
\hline Astronomia & $\begin{array}{l}\text { Ballestería } \\
\text { Blason }\end{array}$ \\
\hline Botánica & Botánica \\
\hline \multirow[t]{7}{*}{ Cirurgía } & Cirugía \\
\hline & Cabestrería \\
\hline & Cantería \\
\hline & Carpintería \\
\hline & Catòptrica \\
\hline & Cerería \\
\hline & Cerrajería \\
\hline
\end{tabular}




\begin{tabular}{|l|l|} 
& Cetrería \\
Comers & Arte de cocina \\
Cronología & Comercio \\
& Cronología \\
& Dióptrica \\
& Dogmática \\
& Dramática \\
Dialéctica & Dialéctica \\
& Estática \\
Escultura & Escultura \\
Esgrima & Esgrima \\
\hline
\end{tabular}

\section{Cuestiones de microestructura}

11) El diccionario se caracteriza por incorporar, además de la indicación típica del equivalente, una definición normalmente completa. Las definiciones son variadas y presentan un marcado carácter semasiológico (aunque no son excepciones las definiciones con orientación onomasiológica, especialmente las de voces de marinería). En el prólogo del diccionario catalán-castellano, el autor precisa que "També he procurat, ademès de la exactitut possible en las definicions, la indicació de algunas paraulas sinónimas, que, si bè convenen ab la principal en lo essencial de la idea, se diferencian en algunas circunstancias ó accessoris, de tot lo que, conegut baix lo nom de sinónims ni ha tanta abundancia en los tres idiomas." En el prólogo del sentido castellano-catalán no se mencionan detalles sobre las definiciones, pero son inferibles de los artículos. En general, se constatan distintos rasgos distintivos de las definiciones:

a) Mantienen un marcado carácter ideológico:

CALVINISME. m. Secta de Calvino, que lo any 1685 fou desterrada de Fransa per lo edicte de Nantes. Entre los mòlts errors del Calvinisme sòn: que Deu predestina ó reproba sols perque vol, sens aténdrer á mérit ni demérit: que dona als predestinats una fé que no poden pérdrer, y una gracia quels priva la llibertat; quels justos no poden, a causa del pecat original, fer ninguna obra bona, ni estan obligats á ferla ni á guardar los manaments: y altres errors condemnats per la escriptura, concilis, sants Papes y per la Iglesia universal. Alguns diuhen quels errors de Calvino son 1400. Calvinismo. Calvinismus, i, calvini secta, doctrina, sodalitium.

b) Tienen un marcado carácter culturalizado en los dos sentidos del diccionario, aunque no siempre en las mismas unidades: 


\section{Castellano-catalán}

PROBLEMA. m. Cuestion que regularmente se propone para ejercitar el ingenio, y se puede defender negativa y afirmativamente con razones en pro y en contra. Problema. Problema. $\|$ mat. La propuesta que se hace de investigar alguna verdad desconocida, ó de practicar alguna cosa. Tales son hallar la razon entre el diámetro y la circunferencia del círculo, medir una distancia inaccesible. Problema. Problema. \| INDETERMINADO. alg. El que admite infinitas ó muchas resoluciones, como son describir un círculo por dos puntos dados, hallar dos números cuya suma sea igual a 20. Problema indeterminat local. Problema indeterminatum.

\begin{tabular}{|c|c|}
\hline Catalán-castellano & Castellano-catalán \\
\hline $\begin{array}{l}\text { JURAT, DA. p.p. Jurado. Juratus. } \| \text { m. En } \\
\text { algunas parts dignitat equivalent á regidor. Jurado, } \\
\text { regidor. Juratus. \| Tribunal de orígen ingles } \\
\text { introduhit ja en altras nacions, y está encarregat de } \\
\text { declarar y determinar lo fet, quedant al cuydado } \\
\text { dels magistrats la designació de la pena que per les } \\
\text { lleys correspon al mateix. També se anomena així } \\
\text { cada un dels individuos que componen dit tribunal. } \\
\text { Jurado. Tribunal in quo factum discernitur. } \\
\text { JURAT EN CAP. En la corona de Aragó era lo } \\
\text { primer dels jurats que se elegía dels ciutadans mès } \\
\text { il-lustres que ja habian estat insaculats en altras } \\
\text { bossas de jurats, y que tenian } 40 \text { anys cumplerts. } \\
\text { Primer jurado. Decurionum primus. }\end{array}$ & $\begin{array}{l}\text { JURADO. m. El sugeto elegido para atender al } \\
\text { bien comun, en particular en la provision de } \\
\text { víveres. Jurat. Decurio. \| EN CAP. En la corona de } \\
\text { Aragon era el primero de los jurados. Jurat en cap. } \\
\text { Decurionum primus. } \| \text { Tribunal de orígen inglés, } \\
\text { introducido ya en otras naciones, cuyo cargo es } \\
\text { determinar y declarar el hecho, quedando al } \\
\text { cuidado de los magistrados la designacion de la } \\
\text { pena que por las leyes corresponde al mismo. } \\
\text { Llámase tambien así cada uno de los individuos } \\
\text { que componen dicho tribunal. Jurat. Tribunal in } \\
\text { quo factum discernitur. }\end{array}$ \\
\hline
\end{tabular}

\section{Catalán-castellano}

JUVENTUT. f. Edat que alguns senyalan dels 23 anys als 33, y altres fins á 35 y altres anyadeixen á la edat viril. [...]

c) La forma habitual de la definición es la aristotélica, iniciada con un descriptor seguido de un conjunto de rasgos distintivos:

PROCÓNSOL Ó PROCÓNSUL. m. Magistrat romá, gobernador de provincia ó general extraordinari de un exêrcit ab jurisdicció é insignias consulars. Procónsul.

d) Suele seguir el modelo aristotélico, pero en algunos casos de presentan de forma sinonímica: 


\begin{tabular}{|c|c|}
\hline Castellano-catalán & Catalán-castellano \\
\hline $\begin{array}{l}\text { DESATINO. Despropósit, disbarat, bojería. } \\
\text { Desatino, locura, sinrazón, desbarro. }\end{array}$ & $\begin{array}{l}\text { NOU, VA. adj. Fresch, recent, flamant, } \\
\text { modern. Nuevo. }\end{array}$ \\
\hline
\end{tabular}

e) La sinonimia se mantiene, incluso, en la presentación de los equivalentes:

NOTICIAR. v.a. Avisar, fer saber. Noticiar, notificar, dar noticia, poner en noticia.

12) El tratamiento de las equivalencias merece un apartado destacado. Todos los lemas en el sentido castellano-catalán, y la mayoría en el sentido catalán-castellano, ofrecen una o más indicaciones de este tipo. Los equivalentes son léxicos cuando el lema lo precisa, pero el autor no duda en utilizar otros recursos cuando la ocasión lo merece. Destacan los equivalentes funcionales, de forma muy especial en la traducción de las unidades fraseológicas (en la versión catalán-castellano de forma preferente).

a) Equivalentes léxicos. Se proponen en general para las unidades simples, en las que existe poca variación entre catalán y castellano:

\begin{tabular}{|l|l|}
\hline \multicolumn{1}{|c|}{ Catalán-castellano } & Castellano-catalán \\
\hline ADVOCAT $\rightarrow$ Abogado & ABOGADO $\rightarrow$ Advocat \\
CALVO, VA $\rightarrow$ Calvo & GUSANILLO $\rightarrow$ Cuquet \\
RETÓRICH, CA $\rightarrow$ Retórico & PRISIONERO $\rightarrow$ Presoner \\
\hline
\end{tabular}

b) Destacan los equivalentes plurales, sin indicación de uso, especialmente en la versión castellano-catalán:

EVENTO. Evento, esdeveniment, succés, cas

EX-ABRUPTO. Arrebatadament, de repente

EVANGELIO CHICO Ó ABREVIADO. Proverbi, aforisme, sentencia

EVANGELISTA. Evangelista, diaca 
c) Son muy frecuentes los equivalentes funcionales, especialmente en la versión castellano-catalán:

ABORRASCARSE (ponerse el tiempo borrascoso) ${ }^{4}$. Alsarse borrasca

CIRCUNSCRIPCIÓN (lo que reduce á ciertos límites la circunferencia de los cuerpos). Límits de la circumferencia

CISNE (mujer pública). Dona pública

CISQUERO (muñequita de lienzo, dentro de la cual se pone carbon molido, para pasarla por encima de los dibujos que se quieren reglar ó bordar). Munyeca de carbó picat

EVEHENTE. Alt sobre el horisònt

EXTRANJERO, A. Estranger foraster

EXTRAÑAR. Apartarse del tracte de algú

GURRION (tela de seda de torcidillo ó cordoncillo). Roba de seda encordellada

GUSARAPIENTO, A. Ple de cuchs

GUZMAN (el noble que servia al rey con plaza de soldado, pero con la distincion de tal). Soldat distingit

GUZPATARRA. Joch de noys

JUDÍO, A. Monjeta renega

JURA DE TAHUR. Prometensas de mariner

PRINGADA. Torrada enllardada, rosta

d) Los equivalentes de unidades fraseológicas están bien cuidados, especialmente en la versión catalán-castellano:

CALVO DEL TOT Ó COM LO PALMELL DE LA MA. Calvo como una calabaza

PÓSATEHO PER TAP AL CUL. Arrópese con ello

PIXAR FORA DEL TEST. Hermoso atar de rocin, y atábale por la cola; bailar sin son: traer á colacion; salirse de la parva ó del corro.

FEBRACUNILLERA. ter. Se diu del qui aparenta major mal pera no traballar ó peraque lo tracten ab regalo Calentura de pollo por comer gallina

\footnotetext{
${ }^{4}$ La información entre paréntesis corresponde a parte de la definición original. Se incluye a modo de aclaración para ilustrar la adecuación de los equivalentes.
} 
13) Existe un aparato de remisiones, en las dos versiones, que se usa para marcar acepciones anticuadas y remisiones generales de un específico a un genérico:

\begin{tabular}{|l|c|}
\hline \multicolumn{1}{|c|}{ Catalán-castellano } & Castellano-catalán \\
\hline ADZABARA. f. ADZAVARA. & JUR. m. ant. DERECHO. \\
ADZABELLA. f. ant. GAYETA, pedra. & JURIDICIAL. adj. ant. JUDICIAL. \\
CALT, A. adj. ant. CALENT & TESTADA. f. TESTERADA. \\
MENTRES ES CALT SE PELA. ref. DE CALENT EN CALENT SE & \\
PELA & \\
\hline
\end{tabular}

14) Sin ser una indicación habitual, el artículo puede presentar ocasionalmente información gramatical:

EMÉTICH, CA. adj, y també se usa com á substantiu. Lo que ocasiona vómit.

\section{EPÍlOGo}

La lexicografía bilingüe moderna entre el catalán y el castellano tiene ya una larga historia. Conocer los rasgos esenciales de la relación lexicográfica permite no olvidar que la lexicografía actual es heredera de los trabajos y los supuestos de los lexicógrafos de los siglos pasados. La lexicografía actual es, sin ninguna duda, deudora de la lexicografía de los siglos XVI a XIX y, en muchos casos, los avances de la lexicografía bilingüe actual distan mucho de los esfuerzos realizados en épocas anteriores.

Sin diccionarios como el Labernia la lexicografía actual no sería lo que es; y, hasta donde hemos podido comprobar, la lexicografía bilingüe entre el catalán y el castellano basa sus supuestos metodológicos en los mismos supuestos de aquellas obras. En cierto modo constatamos que, si bien los avances de la técnica lexicográfica son innegables, no sucede lo mismo con los avances en el tratamiento lexicográfico de las indicaciones; sería interesante comprobar la variación producida entre las definiciones de Labernia o el tratamiento de la equivalencia en su Diccionari y sus correspondientes indicaciones lexicográficas en diccionarios bilingües actuales; nuestro incipiente estudio nos indica que tal variación es poco significativa, pero a ello deberemos dedicar otras investigaciones futuras. 


\section{REFERENCIAS BIBLIOGRÁFICAS}

CABrÉ, M. T., C. GELPí (1996). "La lexicographie bilingüe catalane contemporaine: analyse et évaluation". Dictionnaires bilingues, C. Boisson et al. (eds.), Lovaina, Duculot, 213-230.

Colón, G. (1979). “Léxico y lexicografía catalanes”. Revista Española de Lingüística 9, 441-461.

Colón, G., A.-J. Soberanas (1986). Panorama de la lexicografia catalana, Barcelona, Biblioteca Universitària, Enciclopèdia Catalana.

HAENSCH, G. (1991). "Katalanische Lexikographie". Wörterbücher, Dictionaries, Dictionnaires. Ein internationales Hadbuch zur Lexikographie, F. J. Hausmann, O. Reichmann, H. E. Wiegand y L. Zgusta (eds.), Berlín / Nueva York, W. de Gruyter, Art. $\mathrm{n}^{\circ} 184,1770-1788$.

RAFEL, J. (2005). Lexicografia, Barcelona, UOC.

RAFEL, J. (2008). "Tradition and Innovation in Catalan Lexicography". 2008: Proceedings of the XIII EURALEX International Congress, E. Bernal y J. DeCesaris (eds.), Barcelona, Institut Universitari de Lingüística Aplicada, Universitat Pompeu Fabra, 3547.

RICO, A., J. SolÀ (1995). Gramàtica i lexicografia catalanes: síntesi histórica, Valencia, Servei de Publicacions de la Universitat de València.

\section{Cristina Gelpí}

cristina.gelpi@upf.edu

Departamento de Traducción y Ciencias del Lenguaje

Universitat Pompeu Fabra

Roc Boronat, 138

08018 Barcelona 